\title{
Desempenho agronômico e componentes da produção de cultivares de soja em duas épocas de semeadura no arenito caiuá
}

\section{Agronomic performance and yield components of soybean cultivars in two sowing dates in the region of caiuá sandstone}

\author{
Mauro Cezar Barbosa ${ }^{1 *}$; Alessandro de Lucca e Braccini²; Carlos Alberto Scapim²; \\ Leandro Paiola Albrecht ${ }^{3}$; Gleberson Guillen Piccinin ${ }^{4}$; Claudemir Zucareli ${ }^{5}$
}

\section{Resumo}

O objetivo foi avaliar o desempenho agronômico e os componentes da produção de cultivares de soja (Glycine $\max (\mathrm{L}$.) Merrill) em duas épocas de semeadura e três safras na região do Arenito Caiuá. As cultivares avaliadas foram BRS 255 RR, CD 202, CD 214 RR, BRS 232, BRS 246 RR, CD 208, BRS 262 e CD 218 em três anos agrícolas (2005/2006, 2006/2007 e 2007/2008) e duas épocas de semeadura (27/10 e 10/11). Os ensaios foram dispostos no delineamento em blocos ao acaso, com quatro repetições. As características agronômicas e os componentes de produção avaliados foram: número de dias para maturação, altura de inserção da primeira vagem, número de vagens por planta, massa de cem sementes e produtividade de grãos. A primeira época de semeadura favoreceu o aumento do ciclo de praticamente todas as cultivares nos três anos agrícolas, em comparação com a segunda época. Para todas as cultivares avaliadas a altura de inserção da primeira vagem ficou abaixo do valor recomendado para colheita mecânica para as duas épocas em todas as safras, com exceção da segunda época de semeadura no primeiro ano agrícola. A massa de cem sementes e a produtividade de grãos foram superiores no primeiro ano agrícola. A cultivar BRS 246 RR foi a mais produtiva em ambas as épocas de semeadura no primeiro ano agrícola. As cultivares de ciclo mais longo e épocas de semeadura mais tardias favorecem o desempenho produtivo da soja na região do Arenito Caiuá.

Palavras-chave: Glycine max, produtividade, ciclo, Região do Arenito Caiuá

\begin{abstract}
This work was conducted with the aim of assessing the agronomic performance and yield components of soybean (Glycine $\max$ (L.) Merrill) cultivars in two sowing dates and three crop seasons in the Caiuá Sandstone region. The evaluated cultivars were BRS 255 RR, CD 202, CD 214 RR, BRS 232, BRS 246 RR, CD 208, BRS 262 and CD 218 in three crop seasons (2005/2006, 2006/2007 and 2007/2008) settled in two sowing dates (10/27 and 11/10). The trials were arranged in randomized block design, with four replications. The agronomic characteristics and yield components assessed were: number of days for maturation, insertion height of the first pod, number of pods per plant, 100 seed weight and grain yield. The first sowing date favored increasing the number of days for maturation of virtually all agricultural cultivars in three crop seasons, compared with the second sowing date. For all the evaluated cultivars
\end{abstract}

\footnotetext{
${ }^{1}$ Pesquisador Dr. em Produção Vegetal pela Universidade Estadual de Maringá, UEM, Maringá, PR. E-mail: mcezarbarbosa@ yahoo.com.br

2 Profs. Drs. do Dept ${ }^{0}$ de Agronomia, UEM, Maringá, PR. E-mail: albraccini@uol.com.br; cascapim@uem.br

${ }^{3}$ Prof. Dr. Universidade Federal do Paraná, UFPR, Campus Palotina, PR. E-mail: lpalbrecht@yahoo.com.br

${ }^{4}$ Discente do curso de Pós-Graduação em Agronomia, UEM, Maringá, PR. E-mail: guillen.piccinin@hotmail.com

${ }^{5}$ Prof. Dr. do Dept ${ }^{\mathrm{o}}$ de Agronomia, Universidade Estadual de Londrina, UEL, Londrina, PR. E-mail: claudemircca@uel.br

* Autor para correspondência
} 
the insertion height of the first pods was below the recommended value for mechanical harvesting for the two sowing dates in all vintages, with the exception of the second sowing date in the first agricultural year. The mass of a hundred seeds and grain yield were higher in the first crop season. BRS 246 RR cultivar was the most productive in both sowing dates in first agricultural year evaluated. The longest cycle cultivars and later sowing dates furthers the performance of the yield components in the region of Caiuá Sandstone.

Key words: Glycine max, yield, days for maturation, Caiuá sandstone region

\section{Introdução}

A soja (Glycine max (L.) Merrill) é considerada mundialmente, como a principal fonte de óleos e proteínas vegetais para alimentação humana e animal. A soja constitui, atualmente, um dos produtos de maior importância na economia brasileira, ocupando lugar de destaque na oferta de óleo para consumo interno, como fonte protéica no arraçoamento animal, bem como na pauta de exportação de grãos do país (DALL'AGNOL; HIRAKURI, 2008).

Essa oleaginosa vem sendo cultivada em praticamente todas as regiões do território brasileiro, em virtude do avanço nos trabalhos de pesquisa, representando cerca de $27,9 \%$ da produção mundial, o que coloca o país como segundo maior produtor dessa oleaginosa. No contexto agroindustrial, há mais 40 anos, o "complexo soja" lidera absoluto a pauta de exportações do agronegócio brasileiro (USDA, 2012; CONAB, 2012).

Acultura da soja tem sido alvo de intensa atividade de pesquisa dirigida à obtenção de informações que possibilitem aumentos na produtividade e redução nos custos de produção. Isso requer a constante reformulação e adaptação de novas técnicas de cultivo. Ecofisiologicamente durante o seu ciclo a cultura da soja é exigente em vários fatores, como o fotoperiódico, o térmico e o hídrico. Desta forma, é relevante destacar a escolha da época de semeadura, como sendo o fator cultural que isoladamente mais influencia no desenvolvimento das plantas e na produção da lavoura. A avaliação do comportamento agronômico de cultivares de soja em diferentes épocas de semeadura, em determinada região, é de importância fundamental na indicação do período mais favorável de cultivo.
No Estado do Paraná, a época de semeadura indicada, para a maioria das cultivares, estendese de 15/10 a 15/12. Os melhores resultados, para rendimento e altura de plantas, na maioria dos anos e para a maioria das cultivares, são obtidos nas semeaduras realizadas entre o ultimo decêndio de outubro ao ultimo decêndio de novembro (EMBRAPA, 2011).

A soja tem sido expansivamente utilizada na região do Arenito Caiuá, como alternativa na reforma de pastagens degradadas ou reforma em áreas de cana-de-açúcar. Contudo, sem grandes expectativas de sucesso de produtividade devido às características edafoclimáticas e a carência de informações para a referida região. Portanto, é extremamente válida a realização de estudos que permitam a consolidação de épocas de semeadura para as cultivares mais indicadas para região de Umuarama.

O trabalho tem por objetivo avaliar o desempenho agronômico e os componentes da produção de cultivares de soja em diferentes épocas de semeadura e safras, visando recomendar a época de semeadura mais adequada para a região do Arenito Caiuá.

\section{Material e Métodos}

Os experimentos foram conduzidos nos anos agrícolas de 2005/2006 (ano 1), 2006/2007 (ano 2) e 2007/2008 (ano 3), na Fazenda do Campus Regional de Umuarama (Figura 1A), pertencente à Universidade Estadual de Maringá, localizada em Umuarama - PR. O município de Umuarama está localizado na região noroeste do Estado do Paraná, com altitude de $480 \mathrm{~m}, 23^{\circ} 44^{\prime} \mathrm{S}$ de latitude e $53^{\circ} 17^{\prime} \mathrm{W}$ de longitude. 
O solo da área experimental é classificado como Latossolo Vermelho distrófico (EMBRAPA, 2006a) de textura arenosa. Os resultados da análise química do solo são apresentados na Tabela 1. A adubação foi realizada de acordo com as recomendações técnicas para a cultura da soja (EMBRAPA, 2006b), e as demais práticas culturais conforme preconizado pelo sistema de produção da região.

Tabela 1. Resultados da análise de fertilidade do solo na camada de 0-0,20 m, antes da implantação da cultura em 2005, Umuarama, PR.

\begin{tabular}{|c|c|c|c|c|c|c|c|c|c|c|c|c|}
\hline \multicolumn{13}{|c|}{ Umuarama } \\
\hline Profundidade & $\mathrm{P}^{1}$ & $\mathrm{pH}$ & & $\mathrm{H}^{+}+\mathrm{Al}^{3+}$ & $\mathrm{Al}^{3+}$ & $\mathrm{K}^{1}$ & $\mathrm{Ca}^{3}$ & $\mathrm{Mg}^{3}$ & SB & CTC & V & $\mathrm{C}^{4}$ \\
\hline $\mathrm{m}$ & $\mathrm{mg} \mathrm{dm}^{-3}$ & $\mathrm{CaCl}_{2}$ & $\mathrm{H}_{2} \mathrm{O}$ & ------- & & $---\mathrm{cm}$ & 1ol $\mathrm{dm}^{-}$ & & & ---- & $\%$ & $\mathrm{~g} \mathrm{dm}^{-3}$ \\
\hline $0-0,20$ & 2 & 4,2 & 5,2 & 0,60 & 4,1 & 0,16 & 0,97 & 0,57 & 1,70 & 6,31 & 26,98 & 12,01 \\
\hline
\end{tabular}

${ }^{1}$ Extrator Mehlich $1 ;{ }^{2} \mathrm{CaCl}_{2} 0,01 \mathrm{~mol} \mathrm{~L}^{-1} ;{ }^{3} \mathrm{KCl} 1 \mathrm{~mol} \mathrm{~L}^{-1} ;{ }^{4}$ Método Walkley-Black.

Fonte: Elaboração dos autores.

O clima predominante na região é do tipo Cfa (mesotérmico úmido, com chuvas abundantes no verão e inverno seco com verões quentes), segundo classificação de Köppen. Os dados climáticos locais de precipitação pluviométrica, temperatura máxima e mínima diária, referentes ao período de duração dos ensaios, foram coletados diariamente na estação climatológica do IAPAR, localizada a $20 \mathrm{~km}$ do experimento e apresentados nas Figuras 1, 2 e 3 (IAPAR, 2008).
Foram instalados seis ensaios de competição com oito cultivares de soja, CD 202, CD 214 RR (grupo de maturação precoce), BRS 232, BRS 255 RR, CD 208 (semiprecoce), BRS 246 RR, BRS 262 e CD 218 (médio). A semeadura da soja foi realizada em vinte e sete de outubro (época $1=\mathrm{EP} 1$ ) e dez de novembro (época 2 = EP2), esquematizados em cada gráfico de clima, conjuntamente com os períodos vegetativos $(\mathrm{Vn})$ e reprodutivos $(\mathrm{Rn})$; para os três anos agrícolas.

Figura 1. Temperaturas máximas, mínimas e precipitação pluvial de setembro a março do ano agrícola 2005/2006 em Umuarama, PR.

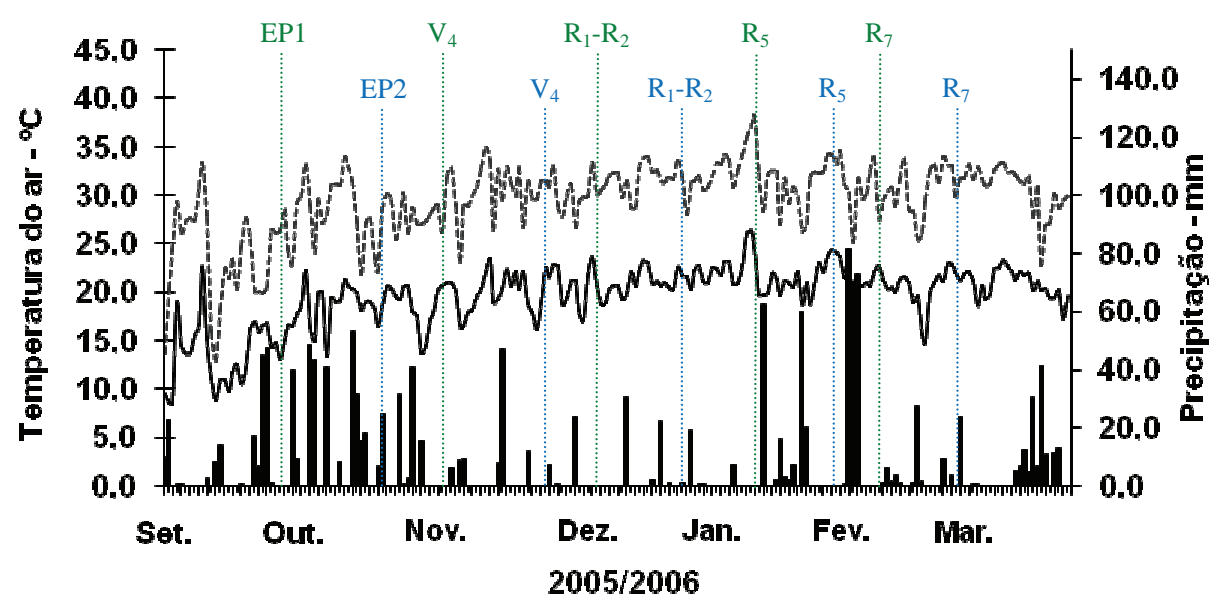

Precipitação Tmáx. Tmín

Fonte: Elaboração dos autores. 
Figura 2. Temperaturas máximas, mínimas e precipitação pluvial de setembro a março do ano agrícola 2006/2007 em Umuarama, PR.

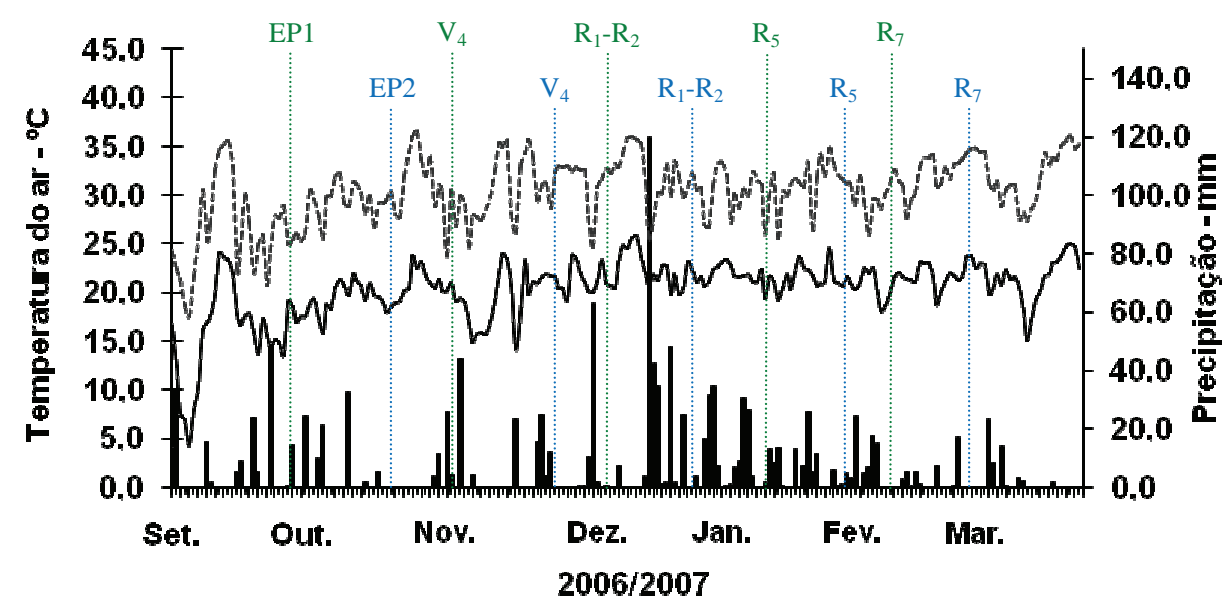

Precipitação

Tmáx.

Tmín

Fonte: Elaborado pelos autores.

Figura 3. Temperaturas máximas, mínimas e precipitação pluvial de setembro a março do ano agrícola 2007/2008 em Umuarama, PR.

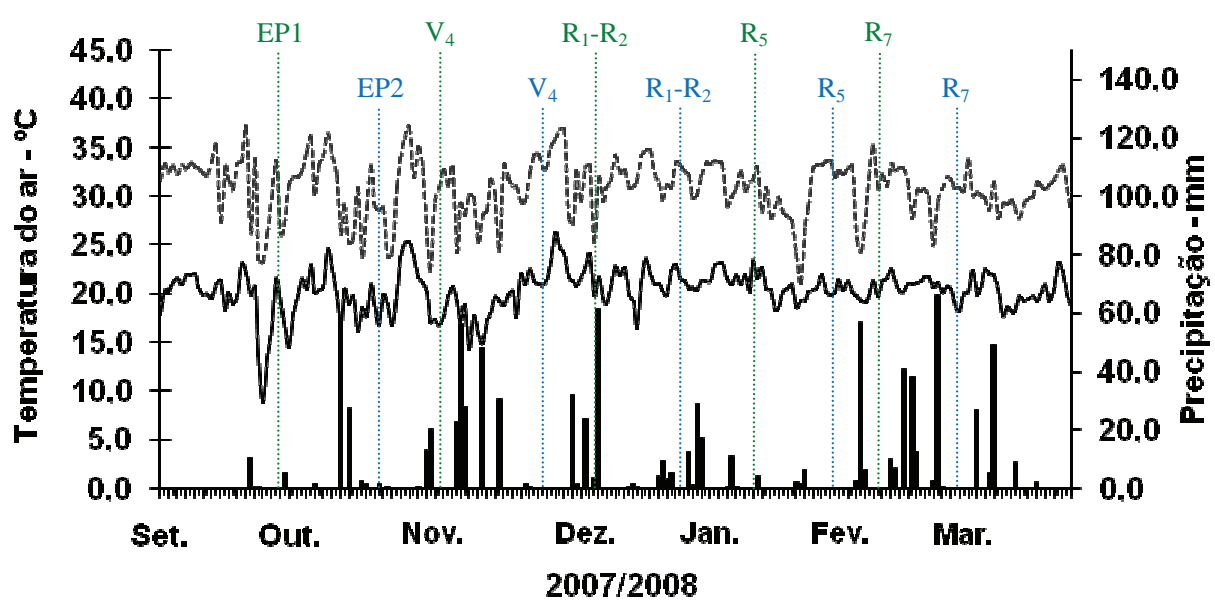

Tmáx.

Tmín

Fonte: Elaboração dos autores.

As parcelas foram constituídas de oito linhas de cinco metros de comprimento, espaçadas de $0,45 \mathrm{~m}$ entre si. Na colheita, foram eliminadas duas linhas externas de cada lado da parcela, bem como $0,5 \mathrm{~m}$ de cada extremidade como bordadura. A área útil da unidade experimental foi de $7,2 \mathrm{~m}^{2}$.
Para a instalação do experimento foram utilizadas semeadoras manuais. Duas semanas após a emergência das plantas, realizaram-se desbastes obtendo aproximadamente 18 plantas por metro linear. 
As sementes de soja foram tratadas com o fungicida Carboxin+ Thiram (250 ml para $100 \mathrm{~kg}$ de sementes), Cobalto+Molibdênio (150 ml 100 $\mathrm{kg}^{-1}$ de sementes), e inoculante turfoso (250 g 50 $\mathrm{kg}^{-1}$ de semente), com 5 bilhões de células viáveis por grama, à base de Bradyrhizobium japonicum.

As plantas daninhas foram controladas por meio de aplicação de herbicidas pós-emergentes Fomesafen (1 L ha $\left.{ }^{-1}\right)$ e Fluazifop-p-butil + Fomesafen ( $2 \mathrm{~L} \mathrm{ha}^{-1}$ ) e capinas manuais. O controle das pragas foi realizado, sempre que necessário, com pulverizações sistemáticas de inseticidas Endosulfan (1,5 L ha') e Metamidofós (0,500 L ha$\left.{ }^{1}\right)$, até o final do ciclo da cultura.

A colheita foi realizada, manualmente, cinco dias após o estádio de desenvolvimento $\mathrm{R}_{8}$ (FEHR; CAVINESS, 1977), quando as sementes de soja apresentavam grau de umidade abaixo de $15 \mathrm{~g} \mathrm{~kg}^{-}$ 1. Após a colheita, as plantas da área útil de cada parcela foram levadas para a debulha em máquina trilhadora estacionária. As sementes provenientes da trilha mecânica foram limpas com o auxílio de peneiras, secadas em condições naturais e acondicionadas em sacos de papel.

No período da maturação foram efetuadas as seguintes determinações pré-colheita: número de dias para maturação (ciclo), altura de inserção da primeira vagem e número de vagens por planta. A maturação foi determinada quando $95 \%$ das vagens apresentavam coloração de madura. Para a determinação da altura de inserção da primeira vagem e número de vagens por planta, foram avaliadas dez plantas ao acaso na área útil das parcelas, com o auxílio de régua milimetrada, sendo os resultados expressos em centímetros.

Por ocasião da colheita (pós-colheita) foram efetuadas as seguintes determinações: teor de água, massa e produtividade de grãos. Partindo-se do rendimento de grãos nas parcelas, foram calculadas as massas de cem sementes e as produtividades em $\mathrm{kg} \mathrm{ha}^{-1}$. Os dados de produtividade de sementes foram corrigidos para $13 \mathrm{~g} \mathrm{~kg}^{-1}$. O teor de água das sementes foi avaliado por meio do método de estufa a $105^{\circ} \mathrm{C}$ por 24 horas (BRASIL, 2009). A massa de cem sementes foi determinada, por meio da pesagem de oito subamostras de 100 sementes, para cada repetição de campo, com o auxílio de balança analítica ( $\pm 1 \mathrm{mg}$ ) (BRASIL, 2009).

O delineamento experimental foi em blocos casualizados em esquema fatorial (8 x $2 \times 3)$, com quatro repetições, sendo que cada época de semeadura foi constituída de ensaio individual de competição de cultivares de soja, em três anos agrícolas. Atendida as pressuposições básicas, os dados coletados foram submetidos à análise de variância conjunta (PIMENTEL-GOMES; GARCIA, 2002; BANZATTO; KRONKA, 2008). As análises foram realizadas pelo programa computacional Sistema para Análise de Variância SISVAR (FERREIRA, 2000).

As médias foram comparadas pelo método de agrupamento de Scott-Knott (SCOTT; KNOTT, 1974) a 5\% de probabilidade, para avaliação dos efeitos de cultivares dentro de cada época e ano (Cultivar/Época x Ano), enquanto que a comparação entre os anos, para cultivares dentro de épocas (Ano/Cultivar x Época), foi realizada pelo teste Student Newman Keuls (SNK), no mesmo nível de significância $(p<0,05)$. Para verificar o comportamento das variáveis, em função das épocas de semeadura, para cada cultivar dentro dos anos (Época/Cultivar x Ano) o teste F foi conclusivo ( $\mathrm{p}$ $<0,05)$.

\section{Resultados e Discussão}

A análise de variância empregada $(\mathrm{p}<0,05)$ para as variáveis em estudo possibilitou detectar efeitos significativos nas interações de segunda ordem (Cultivar x Época x Ano), exceto para a altura de plantas e número de vagens. Porém, independentemente do efeito significativo nas interações foram realizados os desdobramentos, o que permitiu obter diferenças significativas dentro delas. 
Para a primeira época de semeadura foi observado o maior ciclo para a maioria das cultivares (BRS 232, BRS 255 RR, CD 202, CD 208 e CD 214 RR) no segundo ano agrícola, exceto para a BRS 262, BRS 246 RR e CD 218, em que não ocorreu diferença significativa $(\mathrm{p}>0,05)$ entre as safras (Tabela 2). Para a segunda época de semeadura, observa-se a mesma similaridade no aumento do ciclo no segundo ano agrícola, para as mesmas cultivares, exceto para a cultivar BRS 255 RR.

Tabela 2. Médias do número de dias para a maturação (ciclo) de cultivares de soja, em duas épocas de semeadura e três anos agrícolas, na região do Arenito Caiuá (Umuarama, PR).

\begin{tabular}{lccccccc}
\hline & \multicolumn{3}{c}{${\text { Época } 1^{1}}$} & & & \multicolumn{3}{c}{ Época 2 } \\
\cline { 2 - 5 } \cline { 6 - 8 } Cultivar & Ano 1 & Ano 2 & Ano 3 & & Ano 1 & Ano 2 & Ano 3 \\
\hline BRS 232 & $128,0 \mathrm{~b}$ & $137,5 \mathrm{a}$ & $128,8 \mathrm{~b}$ & & $122,0 \mathrm{~b}$ & $129,8 \mathrm{a}$ & $124,5 \mathrm{~b}$ \\
BRS 262 & $134,0 \mathrm{a}$ & $134,8 \mathrm{a}$ & $136,5 \mathrm{a}$ & & $126,0 \mathrm{~b}$ & $128,0 \mathrm{~b}$ & $133,8 \mathrm{a}$ \\
BRS 246 RR & $131,0 \mathrm{a}$ & $134,0 \mathrm{a}$ & $133,8 \mathrm{a}$ & & $123,0 \mathrm{~b}$ & $123,5 \mathrm{~b}$ & $131,0 \mathrm{a}$ \\
BRS 255 RR & $123,0 \mathrm{c}$ & $133,5 \mathrm{a}$ & $127,0 \mathrm{~b}$ & & $115,0 \mathrm{c}$ & $124,3 \mathrm{~b}$ & $128,5 \mathrm{a}$ \\
CD 202 & $125,0 \mathrm{~b}$ & $140,0 \mathrm{a}$ & $116,5 \mathrm{c}$ & & $118,0 \mathrm{~b}$ & $123,8 \mathrm{a}$ & $112,3 \mathrm{c}$ \\
CD 208 & $128,0 \mathrm{~b}$ & $133,5 \mathrm{a}$ & $128,8 \mathrm{~b}$ & & $121,0 \mathrm{~b}$ & $125,3 \mathrm{a}$ & $116,3 \mathrm{c}$ \\
CD 218 & $136,0 \mathrm{a}$ & $136,5 \mathrm{a}$ & $134,5 \mathrm{a}$ & & $129,0 \mathrm{~b}$ & $128,5 \mathrm{~b}$ & $135,0 \mathrm{a}$ \\
CD 214 RR & $124,0 \mathrm{~b}$ & $133,8 \mathrm{a}$ & $125,8 \mathrm{~b}$ & & $117,0 \mathrm{c}$ & $126,5 \mathrm{a}$ & $120,8 \mathrm{~b}$ \\
\hline Média & 128,6 & 135,4 & 128,9 & & 121,4 & 126,2 & 125,3 \\
\hline C.V.(\%) & 1,29 & & & & & \\
\hline
\end{tabular}

${ }^{1}$ Médias seguidas de mesma letra minúscula na linha, dentro de cada época, não diferem entre si pelo teste Student-Newman-Keuls (SNK), a 5\% de probabilidade.

Fonte: Elaboração dos autores.

$\mathrm{Na}$ avaliação da característica número de dias para maturação das cultivares (Tabela 3), constatou-se que, no primeiro ano agrícola e nas duas épocas de semeadura, as cultivares BRS 262 e CD 218 apresentaram ciclo superior as demais. No segundo ano, na primeira época, observou-se maior ciclo nas cultivares BRS 232, CD 202 e CD 218; para a segunda época, o resultado foi similar com as cultivares BRS 232, BRS 246 RR e CD 218 apresentando o maior ciclo. Para o terceiro ano agrícola, verificaram-se os maiores ciclos nas cultivares BRS 262, BRS 246 RR e CD 218, para a primeira época, ao passo que na segunda época, o maior ciclo foi observado nas cultivares BRS 262 e CD 218. Esses resultados evidenciam que, em média, ocorreu alongamento do ciclo das cultivares CD 202 e CD 214 RR que apresentaram comportamento semiprecoce; a cultivar CD 208 por sua vez, semiprecoce à médio, enquanto que as cultivares BRS 232 e BRS 255 RR apresentaram comportamento médio. De acordo com Embrapa (2011) e Coodetec (2008), as cultivares CD 202 e CD 214 RR são classificadas como pertencentes ao grupo de maturação precoce, ao passo que BRS 232, BRS 255 RR e CD 208 são classificadas como semiprecoce e as cultivares BRS 246 RR, BRS 262 e CD 218, por sua vez, são de ciclo médio.

Os resultados encontrados neste experimento explicados e, em partes corroboram com os dados da literatura. Whigham e Minor (1967) relatam que temperaturas inferiores a $25{ }^{\circ} \mathrm{C}$ podem atrasar o início do florescimento, porém, os dias curtos das semeaduras mais tardias apressam intensamente a maturidade, superando os efeitos retardadores das baixas temperaturas.

De acordo com Martins et al. (1999), observaram que as cultivares de soja reduziram o período de maturação, quando foram semeadas em época tardia, confirmando a influência do fotoperíodo na 
redução do ciclo das cultivares, quando semeadas fora da época recomendada, principalmente para as pertencentes ao grupo de maturação precoce. Este trabalho corrobora com os relatos de outros autores (ATHAYDE; RODRIGUES; ARF, 1984; MEDINA et al., 1997).

Os resultados concernentes à altura de inserção da primeira vagem (Tabela 4) para a primeira época de semeadura indicaram maior altura de inserção de vagem nas cultivares CD 208 e CD 218 no primeiro ano agrícola, em comparação aos demais. Na segunda época de semeadura, as plantas apresentaram variações na altura de inserção da primeira vagem, sendo que o primeiro ano agrícola proporcionou médias superiores para as cultivares BRS 232, BRS 255 RR, CD 202, e CD 214 RR.

Tabela 3. Médias do número de dias para a maturação (ciclo) de cultivares de soja, em três anos agrícolas e duas épocas de semeadura (EP1 e 2.), na região do Arenito Caiuá (Umuarama, PR).

\begin{tabular}{|c|c|c|c|c|c|c|}
\hline \multirow[b]{2}{*}{ Cultivar $^{1}$} & \multicolumn{2}{|c|}{ Ano $1^{2}$} & \multicolumn{2}{|c|}{ Ano 2} & \multicolumn{2}{|c|}{ Ano 3} \\
\hline & EP. 1 & EP. 2 & EP. 1 & EP. 2 & EP. 1 & EP. 2 \\
\hline BRS 232 & $128,0 \mathrm{Ca}$ & $122,0 \mathrm{Bb}$ & $137,5 \mathrm{Aa}$ & $129,8 \mathrm{Ab}$ & $128,8 \mathrm{Ba}$ & $124,5 \mathrm{Db}$ \\
\hline BRS 262 & $134,0 \mathrm{Aa}$ & $126,0 \mathrm{Ab}$ & $134,8 \mathrm{Ba}$ & $128,0 \mathrm{Ab}$ & $136,5 \mathrm{Aa}$ & $133,8 \mathrm{Aa}$ \\
\hline BRS 246 RR & $131,0 \mathrm{Ba}$ & $123,0 \mathrm{Bb}$ & $134,0 \mathrm{Ba}$ & $123,5 \mathrm{Bb}$ & $133,8 \mathrm{Aa}$ & $131,0 \mathrm{Ba}$ \\
\hline BRS 255 RR & $123,0 \mathrm{Da}$ & $115,0 \mathrm{Cb}$ & $133,5 \mathrm{Ba}$ & $124,3 \mathrm{Bb}$ & $127,0 \mathrm{Ba}$ & $128,5 \mathrm{Ca}$ \\
\hline CD 202 & $125,0 \mathrm{Da}$ & $118,0 \mathrm{Cb}$ & $140,0 \mathrm{Aa}$ & $123,8 \mathrm{Bb}$ & $116,5 \mathrm{Ca}$ & $112,3 \mathrm{~Gb}$ \\
\hline CD 208 & $128,0 \mathrm{Ca}$ & $121,0 \mathrm{Bb}$ & $133,5 \mathrm{Ba}$ & $125,3 \mathrm{Bb}$ & $128,8 \mathrm{Ba}$ & $116,3 \mathrm{Fb}$ \\
\hline CD 218 & $136,0 \mathrm{Aa}$ & $129,0 \mathrm{Ab}$ & $136,5 \mathrm{Aa}$ & $128,5 \mathrm{Ab}$ & $134,5 \mathrm{Aa}$ & $135,0 \mathrm{Aa}$ \\
\hline CD 214 RR & $124,0 \mathrm{Da}$ & $117,0 \mathrm{Cb}$ & $133,8 \mathrm{Ba}$ & $126,5 \mathrm{Ab}$ & $125,8 \mathrm{Ba}$ & $120,8 \mathrm{~Eb}$ \\
\hline Média & 128,6 & 121,4 & 135,4 & 126,2 & 128,9 & 125,3 \\
\hline C.V. $(\%)$ & 1,69 & & & & & \\
\hline
\end{tabular}

${ }^{1}$ Médias seguidas de mesma letra maiúscula na coluna, dentro de cada época, não diferem entre si pelo método de agrupamento de Scott-Knott, a $5 \%$ de probabilidade.

${ }^{2}$ Médias seguidas de mesma letra minúscula na linha, dentro de cada ano, não diferem entre si pelo teste F, a 5\% de probabilidade.

Fonte: Elaboração dos autores.

Tabela 4. Médias da altura de inserção da primeira vagem $(\mathrm{cm})$ de cultivares de soja, em duas épocas de semeadura e três anos agrícolas, na região Arenito de Caiuá (Umuarama, PR).

\begin{tabular}{|c|c|c|c|c|c|c|}
\hline \multirow[b]{2}{*}{ Cultivar } & \multicolumn{3}{|c|}{ Época $1^{1}$} & \multicolumn{3}{|c|}{ Época 2} \\
\hline & Ano 1 & Ano 2 & Ano 3 & Ano 1 & Ano 2 & Ano 3 \\
\hline BRS 232 & $7,3 \mathrm{ab}$ & $4,3 \mathrm{~b}$ & $8,1 \mathrm{a}$ & $13,9 \mathrm{a}$ & $6,2 \mathrm{~b}$ & $7,8 \mathrm{~b}$ \\
\hline BRS 262 & 9,9 a & $10,3 \mathrm{a}$ & $5,8 \mathrm{~b}$ & $14,5 \mathrm{a}$ & $8,7 \mathrm{~b}$ & $12,1 \mathrm{a}$ \\
\hline BRS 246 RR & $9,3 \mathrm{a}$ & $8,1 \mathrm{a}$ & $7,0 \mathrm{a}$ & $12,1 \mathrm{a}$ & $10,0 \mathrm{a}$ & $10,0 \mathrm{a}$ \\
\hline BRS 255 RR & $10,1 \mathrm{a}$ & $8,0 \mathrm{ab}$ & $6,4 \mathrm{~b}$ & $15,2 \mathrm{a}$ & $9,8 \mathrm{~b}$ & $9,0 \mathrm{~b}$ \\
\hline CD 202 & $8,7 \mathrm{a}$ & $6,3 \mathrm{a}$ & $7,6 \mathrm{a}$ & $13,5 \mathrm{a}$ & $7,1 \mathrm{c}$ & $10,2 \mathrm{~b}$ \\
\hline CD 208 & $10,8 \mathrm{a}$ & $6,1 \mathrm{~b}$ & $6,5 \mathrm{~b}$ & $11,8 \mathrm{a}$ & $6,3 \mathrm{~b}$ & $9,7 \mathrm{a}$ \\
\hline CD 218 & $12,5 \mathrm{a}$ & $8,5 \mathrm{~b}$ & $6,5 \mathrm{~b}$ & $13,3 \mathrm{a}$ & $10,5 \mathrm{a}$ & $10,7 \mathrm{a}$ \\
\hline CD 214 RR & $8,3 \mathrm{a}$ & $8,0 \mathrm{a}$ & $5,0 \mathrm{a}$ & $10,6 \mathrm{a}$ & $5,9 \mathrm{~b}$ & $6,9 \mathrm{~b}$ \\
\hline Média & 9,6 & 7,4 & 6,6 & 13,1 & 8,1 & 9,6 \\
\hline C.V.(\%) & 23,48 & & & & & \\
\hline
\end{tabular}

${ }^{1}$ Médias seguidas de mesma letra minúscula na linha, dentro de cada época, não diferem entre si pelo teste Student-Newman-Keuls (SNK), a 5\% de probabilidade.

Fonte: Elaboração dos autores. 
$\mathrm{Na}$ Tabela 5, é possível averiguar que, no primeiro ano agrícola, ocorreram diferenças significativas para as cultivares BRS 232, BRS 262, BRS 255 RR e CD 202. No segundo ano, não foram observadas diferenças, ao passo que para o terceiro ano agrícola, ocorreram diferenças para as cultivares BRS 262, CD 208 e CD 214 RR. Essa variação entre os anos se deve ao fator clima, em virtude de uma melhor distribuição de chuvas no estádio inicial da cultura no primeiro e terceiro ano.

Avaliando a altura de inserção da primeira vagem das cultivares, em cada época de semeadura dentro dos anos agrícolas avaliados, constatou-se que para a segunda época no primeiro ano, as cultivares BRS 246 RR, CD 208 e CD 214 RR apresentaram as menores médias na referida característica.
$\mathrm{Na}$ avaliação da característica altura de inserção da primeira vagem das cultivares, em cada época de semeadura dentro dos anos agrícolas avaliados, constatou-se que para a segunda época, as cultivares BRS 246 RR, CD 208 e CD 214 RR apresentaram as menores médias na referida característica. No segundo ano agrícola, na primeira época, as cultivares BRS 262, BRS 246 RR, BRS 255 RR, CD 218 e CD 214 RR obtiveram maior altura de inserção da primeira vagem. As cultivares BRS 232, CD 202 e CD 208, por sua vez, apresentaram as menores médias. No terceiro ano agrícola e na segunda época de semeadura, as cultivares BRS 262, BRS 246 RR, CD 202, CD 208 e CD 218 demonstraram superioridade para altura de inserção da primeira vagem, quando comparadas às cultivares BRS 232, BRS 255 RR e CD 214 RR.

Tabela 5. Médias da altura de inserção da primeira vagem $(\mathrm{cm})$ de cultivares de soja, em três anos agrícolas e duas épocas de semeadura, na região do Arenito Caiuá (Umuarama, PR).

\begin{tabular}{|c|c|c|c|c|c|c|}
\hline \multirow[b]{2}{*}{ Cultivar $^{1}$} & \multicolumn{2}{|c|}{ Ano $1^{2}$} & \multicolumn{2}{|c|}{ Ano 2} & \multicolumn{2}{|c|}{ Ano 3} \\
\hline & EP. 1 & EP. 2 & EP. 1 & EP. 2 & EP. 1 & EP. 2 \\
\hline BRS 232 & $7,3 \mathrm{Ab}$ & $13,9 \mathrm{Aa}$ & $4,3 \mathrm{Ba}$ & $6,2 \mathrm{Ba}$ & $8,1 \mathrm{Aa}$ & $7,8 \mathrm{Ba}$ \\
\hline BRS 262 & $9,9 \mathrm{Ab}$ & $14,5 \mathrm{Aa}$ & $10,3 \mathrm{Aa}$ & 8,7 Aa & $5,8 \mathrm{Ab}$ & $12,1 \mathrm{Aa}$ \\
\hline BRS 246 RR & 9,3 $\mathrm{Aa}$ & $12,1 \mathrm{Ba}$ & $8,1 \mathrm{Aa}$ & $10,0 \mathrm{Aa}$ & $7,0 \mathrm{Aa}$ & $10,0 \mathrm{Aa}$ \\
\hline BRS 255 RR & $10,1 \mathrm{Ab}$ & $15,2 \mathrm{Aa}$ & $8,0 \mathrm{Aa}$ & $9,8 \mathrm{Aa}$ & $6,4 \mathrm{Aa}$ & $9,0 \mathrm{Ba}$ \\
\hline CD 202 & $8,7 \mathrm{Ab}$ & $13,5 \mathrm{Aa}$ & $6,3 \mathrm{Ba}$ & 7,1 Ba & 7,6 Aa & $10,2 \mathrm{Aa}$ \\
\hline CD 208 & $10,8 \mathrm{Aa}$ & $11,8 \mathrm{Ba}$ & $6,1 \mathrm{Ba}$ & $6,3 \mathrm{Ba}$ & $6,5 \mathrm{Ab}$ & 9,7 Aa \\
\hline CD 218 & $12,5 \mathrm{Aa}$ & $13,3 \mathrm{Aa}$ & $8,5 \mathrm{Aa}$ & $10,5 \mathrm{Aa}$ & $6,5 \mathrm{Ab}$ & $10,7 \mathrm{Aa}$ \\
\hline CD 214 RR & 8,3 Aa & $10,6 \mathrm{Ba}$ & $8,0 \mathrm{Aa}$ & $5,9 \mathrm{Ba}$ & $5,0 \mathrm{Aa}$ & $6,9 \mathrm{Ba}$ \\
\hline Média & 9,6 & 13,1 & 7,4 & 8,1 & 6,6 & 9,6 \\
\hline C.V. $(\%)$ & 23,48 & & & & & \\
\hline
\end{tabular}

${ }^{1}$ Médias seguidas de mesma letra maiúscula na coluna, dentro de cada época, não diferem entre si pelo método de agrupamento de Scott-Knott, a 5\% de probabilidade.

${ }^{2}$ Médias seguidas de mesma letra minúscula na linha, dentro de cada ano, não diferem entre si pelo teste $\mathrm{F}$, a $5 \%$ de probabilidade. Fonte: Elaboração dos autores.

A altura de inserção da primeira vagem pode ser característica da própria cultivar. Entretanto, quando a semeadura é realizada em épocas inadequadas, a altura de plantas é reduzida havendo tendência de desenvolvimento de vagens próximas ao solo. De acordo com vários autores (GUIMARÃES et al., 2008; BASTIDAS; SETRYONO; DOBERMANN, 2008) os fatores ambientais e/ou práticas culturais afetam altura de inserção de vagens e a altura da planta. Contudo, o fator tipo de solo também pode estar envolvido, especialmente em se tratando de solos mais arenosos, com baixa capacidade de retenção de água e menor fertilidade natural, como a maioria dos solos encontrados na região do Arenito Caiuá, onde o experimento foi instalado. 
A cultivar escolhida para cultivo em uma determinada localidade deve apresentar altura de inserção da primeira vagem de pelo menos 10$12 \mathrm{~cm}$, o que raramente foi observado no estudo realizado, em que as médias de altura de inserção ficaram abaixo do valor indicado para que possa efetuar uma colheita mecânica eficiente das plantas, minimizando as perdas (YOKOMIZO, 1999). As exceções ocorreram na segunda época de semeadura no primeiro ano agrícola, em que as médias das alturas variaram de 10,6 a 15,2 cm. As perdas na colheita mecânica podem chegar a níveis elevados, quando a soja é semeada em época inadequada, devido ao porte baixo das plantas (EMBRAPA, 2011).

De acordo com os resultados obtidos no trabalho, podemos observar que a época de semeadura possui grande influência no desempenho agronômico e nos componentes da produção da cultura. As condições que mais afetam o desenvolvimento da soja são as que envolvem variações nos fatores meteorológicos, tais como: temperatura, umidade do solo e, principalmente, fotoperíodo (PEIXOTO et al., 2001).

Na Tabela 6 são apresentados os dados referentes ao número de vagens por planta das diferentes cultivares de soja avaliadas. Observa-se que houve diferença significativa somente na cultivar CD 202 para primeira época de semeadura, onde o número de vagens foi maior no segundo ano agrícola em relação ao terceiro. Na segunda época de semeadura observou-se na cultivar CD 208 maior número de vagens por planta no segundo ano agrícola, quando comparado a primeira e terceira safras.

Tabela 6. Médias do número de vagens por planta de cultivares de soja, em duas épocas de semeadura e três anos agrícolas, na região do Arenito Caiuá (Umuarama, PR).

\begin{tabular}{|c|c|c|c|c|c|c|}
\hline \multirow[b]{2}{*}{ Cultivar } & \multicolumn{3}{|c|}{ Época $1^{1}$} & \multicolumn{3}{|c|}{ Época 2} \\
\hline & Ano 1 & Ano 2 & Ano 3 & Ano 1 & Ano 2 & Ano 3 \\
\hline BRS 232 & $61,4 \mathrm{a}$ & $55,1 \mathrm{a}$ & $48,3 \mathrm{a}$ & $37,2 \mathrm{a}$ & $40,1 \mathrm{a}$ & $39,3 \mathrm{a}$ \\
\hline BRS 262 & $65,4 \mathrm{a}$ & $69,2 \mathrm{a}$ & 78,9 a & $59,8 \mathrm{a}$ & $64,9 \mathrm{a}$ & $53,3 \mathrm{a}$ \\
\hline BRS 246 RR & $58,3 \mathrm{a}$ & $62,7 \mathrm{a}$ & $47,2 \mathrm{a}$ & $50,8 \mathrm{a}$ & $45,3 \mathrm{a}$ & $37,0 \mathrm{a}$ \\
\hline BRS 255 RR & $60,5 \mathrm{a}$ & 56,3 a & $48,3 \mathrm{a}$ & $33,1 \mathrm{a}$ & $42,0 \mathrm{a}$ & $37,3 \mathrm{a}$ \\
\hline CD 202 & $48,0 \mathrm{ab}$ & $60,7 \mathrm{a}$ & $38,0 \mathrm{~b}$ & $40,7 \mathrm{a}$ & $12,9 \mathrm{a}$ & $37,6 \mathrm{a}$ \\
\hline CD 208 & $58,9 \mathrm{a}$ & $61,5 \mathrm{a}$ & $52,4 \mathrm{a}$ & $38,3 \mathrm{~b}$ & $54,2 \mathrm{a}$ & $36,2 \mathrm{~b}$ \\
\hline CD 218 & 66,2 a & $70,6 \mathrm{a}$ & 59,6 a & $37,7 \mathrm{a}$ & $48,8 \mathrm{a}$ & $35,1 \mathrm{a}$ \\
\hline CD 214 RR & $63,1 \mathrm{a}$ & $53,4 \mathrm{a}$ & $61,1 \mathrm{a}$ & $44,4 \mathrm{a}$ & $49,1 \mathrm{a}$ & $43,5 \mathrm{a}$ \\
\hline Média & 60,2 & 61,2 & 54,2 & 42,7 & 48,4 & 39,9 \\
\hline C.V.(\%) & 18,39 & & & & & \\
\hline
\end{tabular}

${ }^{1}$ Médias seguidas de mesma letra minúscula na linha, dentro de cada época, não diferem entre si pelo teste Student-Newman-Keuls (SNK), a 5\% de probabilidade.

Fonte: Elaboração dos autores.

O número de vagens por planta entre as épocas de semeadura dentro das cultivares para cada ano agrícola é analisado na Tabela 7. Observa-se que no primeiro ano ocorreram diferenças significativas entre as épocas de semeadura. Na primeira época de semeadura, as cultivares BRS 232, BRS 255 RR, CD 208, CD 218 e CD 214 RR apresentaram maior número de vagens por planta. No segundo ano, foram observados resultados similares ao primeiro ano agrícola, em que os maiores números de vagens por planta foram verificados para as cultivares BRS 232, BRS 246 RR, BRS 255 RR, CD 202 e CD 218. No terceiro ano agrícola, foram observados resultados semelhantes ao do primeiro e segundo anos agrícolas, entre as épocas de semeadura. O maior número de vagens por planta foi verificado 
para as cultivares BRS 262, CD 208, CD 218 e CD 214 RR.

Esses resultados indicam que a primeira época de semeadura superou o numero de vagens da segunda época em todos os anos agrícolas para diversas cultivares, possivelmente pela ocorrência de chuvas mais regulares entre os estádios $R_{1}-R_{4}$, reduzindo o abortamento de vagens. Este resultado está de acorso com outros autores, como Farias, Nepomuceno e Neumaier (2007), Matzenauer, Barni e Maluf (2003) e Neumaier et al. (2000), que afirmam a importância do suprimento hídrico nos estádios reprodutivos da cultura da soja.

$\mathrm{Na}$ Tabela 7, constata-se no primeiro ano agrícola e na primeira época de semeadura, que não houve diferença significativa entre as cultivares. Para a segunda época, as cultivares BRS 262 e BRS $246 \mathrm{RR}$ apresentaram maior número de vagens em relação às demais. No segundo ano agrícola, foram observados resultados semelhantes à primeira safra. Para a segunda época de semeadura, o número de vagens foi significativamente superior para as cultivares BRS 262 e CD 208.

Tabela 7. Médias do número de vagens por planta de cultivares de soja, em três anos agrícolas e duas épocas de semeadura, na região do Arenito Caiuá (Umuarama, PR).

\begin{tabular}{|c|c|c|c|c|c|c|}
\hline \multirow[b]{2}{*}{ Cultivar $^{1}$} & \multicolumn{2}{|c|}{ Ano $1^{2}$} & \multicolumn{2}{|c|}{ Ano 2} & \multicolumn{2}{|c|}{ Ano 3} \\
\hline & EP. 1 & EP. 2 & EP. 1 & EP. 2 & EP. 1 & EP. 2 \\
\hline BRS 232 & $61,4 \mathrm{Aa}$ & $37,2 \mathrm{Bb}$ & $55,1 \mathrm{Aa}$ & $40,1 \mathrm{Bb}$ & $48,3 \mathrm{Ca}$ & $39,3 \mathrm{Aa}$ \\
\hline BRS 262 & $65,4 \mathrm{Aa}$ & $59,8 \mathrm{Aa}$ & $69,2 \mathrm{Aa}$ & $64,9 \mathrm{Aa}$ & 78,9 Aa & $53,3 \mathrm{Ab}$ \\
\hline BRS 246 RR & $58,3 \mathrm{Aa}$ & $50,8 \mathrm{Aa}$ & $62,7 \mathrm{Aa}$ & $45,3 \mathrm{Bb}$ & $47,2 \mathrm{Ca}$ & $37,0 \mathrm{Aa}$ \\
\hline BRS 255 RR & $60,5 \mathrm{Aa}$ & $33,1 \mathrm{Bb}$ & $56,3 \mathrm{Aa}$ & $42,0 \mathrm{Bb}$ & $48,3 \mathrm{Ca}$ & $37,3 \mathrm{Aa}$ \\
\hline CD 202 & $48,0 \mathrm{Aa}$ & $40,7 \mathrm{Ba}$ & $60,7 \mathrm{Aa}$ & $12,9 \mathrm{Bb}$ & $38,0 \mathrm{Ca}$ & $37,6 \mathrm{Aa}$ \\
\hline CD 208 & $58,9 \mathrm{Aa}$ & $38,3 \mathrm{Bb}$ & $61,5 \mathrm{Aa}$ & $54,2 \mathrm{Aa}$ & $52,4 \mathrm{Ca}$ & $36,2 \mathrm{Ab}$ \\
\hline CD 218 & 66,2 Aa & $37,7 \mathrm{Bb}$ & $70,6 \mathrm{Aa}$ & $48,8 \mathrm{Bb}$ & $59,6 \mathrm{Ba}$ & $35,1 \mathrm{Ab}$ \\
\hline CD 214 RR & $63,1 \mathrm{Aa}$ & $44,4 \mathrm{Bb}$ & $53,4 \mathrm{Aa}$ & $49,1 \mathrm{Ba}$ & $61,1 \mathrm{Ba}$ & $43,5 \mathrm{Ab}$ \\
\hline Média & 60,2 & 42,7 & 61,2 & 48,4 & 54,2 & 39,9 \\
\hline C.V.(\%) & 18,39 & & & & & \\
\hline
\end{tabular}

${ }^{1}$ Médias seguidas de mesma letra maiúscula na coluna, dentro de cada época, não diferem entre si pelo método de agrupamento de Scott-Knott, a 5\% de probabilidade.

${ }^{2}$ Médias seguidas de mesma letra minúscula na linha, dentro de cada ano, não diferem entre si pelo teste $\mathrm{F}$, a $5 \%$ de probabilidade. Fonte: Elaboração dos autores.

Pode-se ressaltar que a cultivar BRS 262 apresenta certa superioridade (na segunda época do primeiro e segundo anos; e na primeira época do terceiro ano), provavelmente em virtude de ser uma cultivar pertencente ao grupo de maturação médio, sendo o número de dias compreendido entre os estádios $R_{1}$ e $R_{4}$ maior, diminuindo substancialmente o impacto de estresses hídrico e térmico pontuais, ocorridos durante a condução do experimento. Temperaturas elevadas (próximas aos $40^{\circ} \mathrm{C}$ ), principalmente quando associadas à ocorrência de déficit hídrico, tem efeito adverso na taxa de crescimento e provocam distúrbios na floração, diminuindo a capacidade de retenção de vagens (FARIAS; NEPOMUCENO, NEUMAIER, 2007; EMBRAPA, 2011).

É possível visualizar variações entre os anos dentro de cada época de semeadura, em relação à massa de cem sementes (Tabela 8). Para a primeira época de semeadura, o primeiro ano agrícola propiciou maior acúmulo de biomassa seca em comparação ao segundo e ao terceiro anos agrícolas, para as cultivares BRS 246 RR, BRS 255 RR, CD 218 e CD 214 RR. As cultivares BRS 232 e CD 202 
apresentaram maior massa no segundo ano agrícola. $\mathrm{Na}$ segunda época de semeadura, as cultivares apresentaram variações na massa de cem sementes em função dos anos, em que o primeiro ano agrícola apresentou médias superiores aos outros dois anos agrícolas para as cultivares CD 208, CD 218 e CD 214 RR.

De maneira geral, o primeiro ano agrícola superou os demais na massa de cem sementes, com destaque para a cultivar CD 214 RR. Isso se deve às chuvas mais abundantes no mês de fevereiro deste ano, coincidindo com a fase de enchimento de grãos em ambas as épocas, desta forma a massa de cem grãos no segundo e terceiro anos foram prejudicadas em virtude do ambiente. A menor disponibilidade de água promove decréscimo da fotossíntese e abrevia o período de enchimento das sementes, com prejuízo ao acúmulo de biomassa dos grãos e provavelmente à produção (FRANÇA NETO; KRZYZANOWSKI, 1990; WELLS, 1991, 1993; HEIFFIG et al., 2006).

Tabela 8. Médias da massa de cem sementes ( $\mathrm{g}$ ) de cultivares de soja, em duas épocas de semeadura e três anos agrícolas, na região do Arenito Caiuá (Umuarama, PR).

\begin{tabular}{|c|c|c|c|c|c|c|}
\hline \multirow[b]{2}{*}{ Cultivar } & \multicolumn{3}{|c|}{ Época $1^{1}$} & \multicolumn{3}{|c|}{ Época 2} \\
\hline & Ano 1 & Ano 2 & Ano 3 & Ano 1 & Ano 2 & Ano 3 \\
\hline BRS 232 & $17,54 \mathrm{c}$ & $24,15 \mathrm{a}$ & $19,73 \mathrm{~b}$ & $16,04 \mathrm{c}$ & $20,71 \mathrm{a}$ & $18,44 \mathrm{~b}$ \\
\hline BRS 262 & $18,63 \mathrm{a}$ & $16,49 \mathrm{~b}$ & $17,42 \mathrm{ab}$ & $16,25 \mathrm{a}$ & $15,58 \mathrm{a}$ & $16,43 \mathrm{a}$ \\
\hline BRS 246 RR & $18,99 \mathrm{a}$ & $15,13 \mathrm{~b}$ & $15,40 \mathrm{~b}$ & $14,29 \mathrm{ab}$ & $13,59 \mathrm{~b}$ & $15,49 \mathrm{a}$ \\
\hline BRS 255 RR & $18,43 \mathrm{a}$ & $16,88 \mathrm{~b}$ & $16,55 \mathrm{~b}$ & $17,61 \mathrm{a}$ & $15,83 \mathrm{~b}$ & $17,11 \mathrm{ab}$ \\
\hline CD 202 & $17,06 \mathrm{~b}$ & $19,32 \mathrm{a}$ & $15,48 \mathrm{c}$ & $17,18 \mathrm{a}$ & $16,59 \mathrm{a}$ & $15,91 \mathrm{a}$ \\
\hline CD 208 & $17,05 \mathrm{a}$ & $16,54 \mathrm{ab}$ & $15,20 \mathrm{~b}$ & 15,79 a & $14,30 \mathrm{~b}$ & $13,36 \mathrm{~b}$ \\
\hline CD 218 & $19,25 \mathrm{a}$ & $17,27 \mathrm{~b}$ & $16,79 \mathrm{~b}$ & $16,94 \mathrm{a}$ & $15,43 \mathrm{~b}$ & 18,18 a \\
\hline CD $214 \mathrm{RR}$ & $17,96 \mathrm{a}$ & $15,84 \mathrm{~b}$ & $15,12 \mathrm{~b}$ & $15,08 \mathrm{a}$ & $12,49 \mathrm{~b}$ & $13,42 \mathrm{~b}$ \\
\hline Média & 18,11 & 17,70 & 16,46 & 16,15 & 15,57 & 16,04 \\
\hline C.V.(\%) & 6,16 & & & & & \\
\hline
\end{tabular}

${ }^{1}$ Médias seguidas de mesma letra minúscula na linha, dentro de cada época, não diferem entre si pelo teste Student-Newman-Keuls (SNK), a 5\% de probabilidade.

Fonte: Elaboração dos autores.

Analisando a massa de cem sementes das cultivares entre épocas, dentro de cada ano agrícola (Tabela 9), é possível identificar que no primeiro ano agrícola houve diferença significativa ( $p$ $<0,05)$ entre as épocas de semeadura para as cultivares BRS 232, BRS 262 e BRS 246 RR. No segundo ano agrícola, foi constatada diferença significativa entre as épocas de modo semelhante ao primeiro ano. Assim, as cultivares BRS 232, BRS 246 RR, CD 202, CD 208, CD 218 e CD 214 RR apresentaram resultados médios de massa de cem sementes superiores às médias da segunda época de semeadura. No terceiro ano agrícola, ocorreram diferenças significativas entre as épocas de semeadura para duas cultivares CD 208 e CD 214 RR. Portanto, observou-se que, em geral, as médias da primeira época de semeadura foram superiores as da segunda época para o primeiro e segundo anos agrícolas. 
Tabela 9. Médias da massa de cem sementes (g) de cultivares de soja, em três anos agrícolas e duas épocas de semeadura, na região do Arenito Caiuá (Umuarama-PR).

\begin{tabular}{|c|c|c|c|c|c|c|}
\hline \multirow[b]{2}{*}{ Cultivar $^{1}$} & \multicolumn{2}{|c|}{ Ano $1^{2}$} & \multicolumn{2}{|c|}{ Ano 2} & \multicolumn{2}{|c|}{ Ano 3} \\
\hline & EP. 1 & EP. 2 & EP. 1 & EP. 2 & EP. 1 & EP. 2 \\
\hline BRS 232 & $17,54 \mathrm{Ba}$ & $16,04 \mathrm{Bb}$ & $24,15 \mathrm{Aa}$ & $20,71 \mathrm{Ab}$ & $19,73 \mathrm{Aa}$ & $18,44 \mathrm{Aa}$ \\
\hline BRS 262 & $18,63 \mathrm{Aa}$ & $16,25 \mathrm{Bb}$ & $16,49 \mathrm{Ca}$ & $15,58 \mathrm{Ba}$ & $17,42 \mathrm{Ba}$ & $16,43 \mathrm{Ba}$ \\
\hline BRS 246 RR & $18,99 \mathrm{Aa}$ & $14,29 \mathrm{Cb}$ & $15,13 \mathrm{Da}$ & $13,59 \mathrm{Cb}$ & $15,40 \mathrm{Ca}$ & $15,49 \mathrm{Ba}$ \\
\hline BRS 255 RR & $18,43 \mathrm{Aa}$ & $17,61 \mathrm{Aa}$ & $16,88 \mathrm{Ca}$ & $15,83 \mathrm{Ba}$ & $16,55 \mathrm{Ba}$ & $17,11 \mathrm{Aa}$ \\
\hline CD 202 & $17,06 \mathrm{Ba}$ & $17,18 \mathrm{Aa}$ & $19,32 \mathrm{Ba}$ & $16,59 \mathrm{Bb}$ & $15,48 \mathrm{Ca}$ & $15,91 \mathrm{Ba}$ \\
\hline CD 208 & $17,05 \mathrm{Ba}$ & $15,79 \mathrm{Ba}$ & $16,54 \mathrm{Ca}$ & $14,30 \mathrm{Cb}$ & $15,20 \mathrm{Ca}$ & $13,36 \mathrm{Cb}$ \\
\hline CD 218 & $19,25 \mathrm{Aa}$ & $16,94 \mathrm{Aa}$ & $17,27 \mathrm{Ca}$ & $15,43 \mathrm{Bb}$ & $16,79 \mathrm{Ba}$ & $18,18 \mathrm{Aa}$ \\
\hline CD $214 \mathrm{RR}$ & $17,96 \mathrm{Ba}$ & $15,08 \mathrm{Ca}$ & $15,84 \mathrm{Da}$ & $12,49 \mathrm{Db}$ & $15,12 \mathrm{Ca}$ & $13,42 \mathrm{Cb}$ \\
\hline Média & 18,11 & 16,15 & 17,70 & 15,57 & 16,46 & 16,04 \\
\hline C.V.(\%) & 6,16 & & & & & \\
\hline
\end{tabular}

${ }^{1}$ Médias seguidas de mesma letra maiúscula na coluna, dentro de cada época, não diferem entre si pelo método de agrupamento de Scott-Knott, a 5\% de probabilidade.

${ }^{2}$ Médias seguidas de mesma letra minúscula na linha, dentro de cada ano, não diferem entre si pelo teste $\mathrm{F}$, a 5\% de probabilidade. Fonte: Elaboração dos autores.

Para a característica massa de cem sementes das cultivares, em cada época de semeadura dentro dos anos agrícolas (Tabela 9), constatou-se que, na primeira época do primeiro ano, as cultivares BRS 262, BRS 246 RR, BRS 255 RR e CD 218 tiveram o melhor desempenho. No segundo ano, a maior média de massa dos grãos foi verificada para a cultivar BRS 232, tanto na primeira quanto na segunda época de plantio. No terceiro ano, na primeira época, observaram-se diferenças significativas entre as cultivares, em que a BRS 232 apresentou maior média.

Enfatiza-se que a cultivar BRS 232, no segundo e no terceiro anos agrícolas, apresentou as maiores médias. Esperava-se que esse fato realmente fosse notado, em virtude dessa cultivar apresentar características genotípicas que lhe conferem maior massa de grãos (EMBRAPA, 2011). Ressalta-se que as diferenças evidenciadas quanto a massa dos grãos, entre as cultivares, pode ser atribuída a menor ou maior suscetibilidade dos genótipos ás condições de estresse ambientais ocorridas durante desenvolvimento do experimento.
Segundo Medina et al. (1997), condições marcadas por temperaturas elevadas de até $36^{\circ} \mathrm{C}$, e baixa frequência de chuvas, que coincidam com o período de acúmulo de biomassa seca nas sementes (estádios R5 a R7), associado ao solo mais arenoso (drenagem rápida), provoca intensa evapotranspiração, resultando em menor disponibilidade hídrica. A consequência do estresse hídrico durante o desenvolvimento dos grãos pode resultar na menor massa de cada grão, o que está em consonância com Taware et al. (1997); o que também foi observado neste trabalho.

Para a primeira época de semeadura, não foi observada diferença estatística $(p>0,05)$ entre os anos agrícolas quanto à produtividade de grãos (Tabela 10). Na segunda época de semeadura, houve diferenças entre os anos. As cultivares BRS 246 RR, BRS 255 RR, CD 202 e CD 208 no primeiro ano, apresentaram as maiores produtividades, em comparação ao segundo e terceiro anos agrícolas. No primeiro ano, na segunda época, o clima foi mais favorável, com chuvas mais regulares a partir do inicio do florescimento até o enchimento de grãos (Figura 1), o que contribuiu para os resultados de produtividade obtidos. 
Tabela 10. Médias da produtividade $\left(\mathrm{kg} \mathrm{ha}^{-1}\right)$ de cultivares de soja, em duas épocas de semeadura e três anos agrícolas, na região do Arenito Caiuá (Umuarama, PR).

\begin{tabular}{lccccccc}
\hline & \multicolumn{3}{c}{ Época 1 $^{1}$} & & \multicolumn{3}{c}{ Época 2 } \\
\cline { 2 - 4 } \cline { 7 - 8 } Cultivar & Ano 1 & Ano 2 & Ano 3 & & Ano 1 & Ano 2 & Ano 3 \\
\hline BRS 232 & $2539,90 \mathrm{a}$ & $3020,89 \mathrm{a}$ & $3286,42 \mathrm{a}$ & & $2218,49 \mathrm{a}$ & $2509,85 \mathrm{a}$ & $2395,49 \mathrm{a}$ \\
BRS 262 & $2842,60 \mathrm{a}$ & $3325,91 \mathrm{a}$ & $3369,11 \mathrm{a}$ & & $2242,10 \mathrm{a}$ & $2227,99 \mathrm{a}$ & $2255,91 \mathrm{a}$ \\
BRS 246 RR & $2970,14 \mathrm{a}$ & $3130,94 \mathrm{a}$ & $3518,13 \mathrm{a}$ & & $4534,11 \mathrm{a}$ & $2365,48 \mathrm{~b}$ & $2271,77 \mathrm{~b}$ \\
BRS 255 RR & $2753,98 \mathrm{a}$ & $3332,17 \mathrm{a}$ & $3299,93 \mathrm{a}$ & & $3373,72 \mathrm{a}$ & $2134,16 \mathrm{~b}$ & $2393,16 \mathrm{~b}$ \\
CD 202 & $2041,83 \mathrm{a}$ & $2822,94 \mathrm{a}$ & $2724,25 \mathrm{a}$ & & $3342,68 \mathrm{a}$ & $1973,52 \mathrm{~b}$ & $2623,47 \mathrm{~b}$ \\
CD 208 & $3087,27 \mathrm{a}$ & $3332,74 \mathrm{a}$ & $2975,67 \mathrm{a}$ & & $3799,82 \mathrm{a}$ & $2466,82 \mathrm{~b}$ & $1848,66 \mathrm{~b}$ \\
CD 218 & $3175,29 \mathrm{a}$ & $3406,42 \mathrm{a}$ & $3224,62 \mathrm{a}$ & & $3210,47 \mathrm{a}$ & $1986,36 \mathrm{~b}$ & $2624,57 \mathrm{ab}$ \\
CD 214 RR & $2889,93 \mathrm{a}$ & $2842,95 \mathrm{a}$ & $3136,62 \mathrm{a}$ & & $3217,01 \mathrm{a}$ & $2194,85 \mathrm{~b}$ & $2669,96 \mathrm{ab}$ \\
\hline Média & 2787,62 & 3151,87 & 3191,84 & & 3242,35 & 2232,38 & 2385,37 \\
\hline C.V.(\%) & 16,78 & \multicolumn{5}{c}{} \\
\hline
\end{tabular}

${ }^{1}$ Médias seguidas de mesma letra minúscula na linha, dentro de cada época, não diferem entre si pelo teste Student-Newman-Keuls (SNK), a 5\% de probabilidade.

Fonte: Elaboração dos autores.

Comparando as épocas de semeadura, observase na segunda época (Tabela 11) que as cultivares BRS 246 RR, CD 202 e CD 208 apresentaramse com produtividade superior à primeira época; No segundo ano agrícola, foi possível constatar diferenças significativas $(\mathrm{p}<0,05)$ entre as épocas, para as cultivares BRS 262, BRS 246 RR, BRS 255 RR, CD 202 e CD 218, que apresentaram resultados médios de produtividade superiores na primeira época de semeadura. No terceiro ano, ocorreram diferenças significativas entre as épocas para as cultivares BRS 232, BRS 262, BRS 246 RR, BRS 255 RR e CD 208.

Quanto à produtividade em cada época de semeadura dentro dos anos agrícolas (Tabela 11), na primeira época do primeiro ano, as cultivares BRS 262, BRS 246 RR, BRS 255 RR, CD 208, CD 218 e CD 214 RR tiveram o melhor desempenho. As cultivares BRS 232 e CD 202, por sua vez, obtiveram as menores produtividades. Para a segunda época, somente a cultivar BRS 246 RR apresentou maior média de produtividade, seguida pela BRS 255 RR, CD 202, CD 208, CD 218 e CD 214 RR. A cultivar BRS 246 RR apresentou superioridade em ambas as épocas de semeadura no primeiro ano agrícola avaliado. O diferencial produtivo notado na cultivar BRS $246 \mathrm{RR}$, pode ser atribuído ao potencial genotípico inerente, que diante das condições climáticas possibilitou a expressão de altos rendimentos.

Para todas as épocas de semeadura, as oito cultivares foram afetadas por deficiência hídrica, algumas logo nos estádios iniciais de desenvolvimento, outras, principalmente, na fase reprodutiva. Portanto, foi possível verificar o impacto da escolha de determinada época de semeadura, ao longo dos anos, no que se refere ao suprimento das exigências hídricas de alguns genótipos de soja, o que corrobora com os aspectos discutidos por outros autores (RANGEL et al., 2007; ALBRECHT et al., 2008a,b). 
Tabela 11. Médias da produtividade $\left(\mathrm{kg} \mathrm{ha}^{-1}\right)$ de cultivares de soja, em três anos agrícolas e duas épocas de semeadura, na região do Arenito Caiuá (Umuarama, PR).

\begin{tabular}{|c|c|c|c|c|c|c|}
\hline \multirow[b]{2}{*}{ Cultivar $^{1}$} & \multicolumn{2}{|c|}{ Ano $1^{2}$} & \multicolumn{2}{|c|}{ Ano 2} & \multicolumn{2}{|c|}{ Ano 3} \\
\hline & EP. 1 & EP. 2 & EP. 1 & EP. 2 & EP. 1 & EP. 2 \\
\hline BRS 232 & $2539,90 \mathrm{Ba}$ & $2218,49 \mathrm{Ca}$ & $3020,89 \mathrm{Aa}$ & $2509,85 \mathrm{Aa}$ & $3286,42 \mathrm{Aa}$ & $2395,49 \mathrm{Ab}$ \\
\hline BRS 262 & $2842,60 \mathrm{Aa}$ & $2242,10 \mathrm{Ca}$ & $3325,91 \mathrm{Aa}$ & $2227,99 \mathrm{Ab}$ & $3369,11 \mathrm{Aa}$ & $2255,91 \mathrm{Ab}$ \\
\hline BRS 246 RR & $2970,14 \mathrm{Ab}$ & $4534,11 \mathrm{Aa}$ & $3130,94 \mathrm{Aa}$ & $2365,48 \mathrm{Ab}$ & $3518,13 \mathrm{Aa}$ & $2271,77 \mathrm{Ab}$ \\
\hline BRS 255 RR & $2753,98 \mathrm{Aa}$ & $3373,72 \mathrm{Ba}$ & $3332,17 \mathrm{Aa}$ & $2134,16 \mathrm{Ab}$ & $3299,93 \mathrm{Aa}$ & $2393,16 \mathrm{Ab}$ \\
\hline CD 202 & $2041,83 \mathrm{Bb}$ & $3342,68 \mathrm{Ba}$ & $2822,94 \mathrm{Aa}$ & $1973,52 \mathrm{Ab}$ & $2724,25 \mathrm{Aa}$ & $2623,47 \mathrm{Aa}$ \\
\hline CD 208 & $3087,27 \mathrm{Ab}$ & $3799,82 \mathrm{Ba}$ & $3332,74 \mathrm{Aa}$ & $2466,82 \mathrm{Ab}$ & $2975,67 \mathrm{Aa}$ & $1848,66 \mathrm{Ab}$ \\
\hline CD 218 & $3175,29 \mathrm{Aa}$ & $3210,47 \mathrm{Ba}$ & $3406,42 \mathrm{Aa}$ & $1986,36 \mathrm{Ab}$ & $3224,62 \mathrm{Aa}$ & $2624,57 \mathrm{Aa}$ \\
\hline CD 214 RR & $2889,93 \mathrm{Aa}$ & $3217,01 \mathrm{Ba}$ & $2842,95 \mathrm{Aa}$ & $2194,85 \mathrm{Aa}$ & $3136,62 \mathrm{Aa}$ & $2669,96 \mathrm{Aa}$ \\
\hline Média & 2787,62 & 3242,35 & 3151,87 & 2232,38 & 3191,84 & 2385,37 \\
\hline C.V.(\%) & 16,78 & & & & & \\
\hline
\end{tabular}

${ }^{1}$ Médias seguidas de mesma letra maiúscula na coluna, dentro de cada época, não diferem entre si pelo método de agrupamento de Scott-Knott, a 5\% de probabilidade.

${ }^{2}$ Médias seguidas de mesma letra minúscula na linha, dentro de cada ano, não diferem entre si pelo teste $\mathrm{F}$, a 5\% de probabilidade. Fonte: Elaboração dos autores.

Para Cunha et al. (2001), a soja pode ser considerada uma cultura tolerante à deficiência hídrica, por possuir período de florescimento longo. No entanto, a deficiência hídrica submete a planta de soja a estresse que se manifesta na forma de baixa estatura, folhas pequenas, entrenós curtos, menor índice de área foliar, menor taxa de expansão foliar e prejuízos à fixação de nitrogênio (CONFALONE; DUJMOVICH, 1999; DESCLAUX; HUYNH; ROUMET, 2000). Secas durante o período reprodutivo (pós-florescimento) causam reduções drásticas no rendimento de grãos, devido ao maior abortamento de flores e de vagens, menor período de florescimento, menor número de grãos por vagem e menor período de enchimento de grãos. Estas perdas, em algumas ocasiões, acabam não sendo compensadas pelo número de grãos por vagem e pela massa do grão, pois esses componentes do rendimento possuem limites máximos determinados geneticamente (DE SOUZA; EGLI, BRUENING, 1997). Os resultados obtidos neste trabalho estão de acordo com Peixoto et al. (2001), de que existe grande variabilidade entre as cultivares com relação à sensibilidade a época de semeadura e às mudanças na região de cultivo.
Desta forma, as condições que mais afetam o desenvolvimento da soja são as que envolvem variações dos fatores climáticos, e quando levamos em consideração a época de semeadura e o ambiente de cultivo.

\section{Conclusões}

A primeira época de semeadura favoreceu o aumento do ciclo de praticamente todas as cultivares nos três anos agrícolas, em comparação com a segunda época.

A altura de inserção da primeira vagem ficou abaixo do valor recomendado para colheita mecânica para todas as cultivares nas duas épocas em todas as safras, com exceção da segunda época de semeadura no primeiro ano agrícola.

A cultivar BRS $246 \mathrm{RR}$ foi a mais produtiva em ambas as épocas de semeadura no primeiro ano agrícola avaliado.

Cultivares de ciclo mais longo e épocas de semeadura mais tardias favorecem o desempenho produtivo da soja na região do Arenito Caiuá. 


\section{Referências}

ALBRECHT, L. P.; BRACCINI, A. L.; ÁVILA, M. R.; SUZUKI, L. S.; SCAPIM, C. A.; BARBOSA, M. C. Teores de óleo, proteína e produtividade de soja em função da antecipação da semeadura na região oeste do Paraná. Bragantia, Campinas, v. 67, n. 4, p. 817-825, 2008 b.

ALBRECHT, L. P.; BRACCINI, A. L.; SCAPIM, C. A.; AGUIAR, C. G.; ÁVILA, M. R.; STÜLP, M. Qualidade fisiológica e sanitária das sementes sob semeadura antecipada da soja. Scientia Agraria, Curitiba, v. 9, n. 4, p. 445-454, 2008a.

ATHAYDE, M. L. F.; RODRIGUES, R.; ARF, O. Comportamento de cultivares de soja em semeadura tardia na região de Jaboticabal (SP). In: SEMINÁRIO NACIONAL DE PESQUISA DE SOJA, 3., Campinas, 1984. Anais... Londrina, EMBRAPA/CNPSo, 1984. p. 441-448.

BANZATTO, D. A.; KRONKA, S. N. Experimentação agrícola. 4. ed. Jaboticabal: FUNEP, 2008. 237 p.

BASTIDAS, A. M.; SETRYONO, T. D.; DOBERMANN, A. Soybean sowing date: the vegetative, reproductive, and agronomic impacts. Crop Science, Madison, v. 48, n. 2, p. 727-740, 2008.

BRASIL. Ministério da Agricultura, Pecuária e Abastecimento. Regras para análise de sementes. Secretaria de Defesa Agropecuária. Brasília, DF: Mapa/ ACS, 2009. 395 p.

COMPANHIA NACIONAL DE ABASTECIMENTO - CONAB. Central de informações agropecuárias: conjuntura agropecuária. 2012. Disponível em: <http:// www.conab.gov.br>. Acesso em: 24 fev. 2012.

CONFALONE, A.; DUJMOVICH, M. N. Influência do déficit hídrico sobre o desenvolvimento e rendimento da soja. Revista Brasileira de Agrometeorologia, Santa Maria, v. 7, n. 2, p.183-187, 1999.

COODETEC. Cultivares de soja 2008. Cascavel: COODETEC, 2008. 55 p.

CUNHA, G. R.; BARNI, N. A.; HAAS, J. C.; MALUF, J. R. T.; MATZENAUER, R.; PASINATO, A.; PIMENTEL, M. B. M.; PIRES, J. L. F. Zoneamento agrícola e época de semeadura para soja no Rio Grande do Sul. Revista Brasileira de Agrometeorologia, Santa Maria, v. 9, n. 3, p. 446-459, 2001.

DALL'AGNOL, A.; HIRAKURI, E. M. H. Realidade e perspectivas do Brasil na produção de alimentos e agroenergia, com ênfase na soja. 2008. Disponível em: $\quad<$ http://www.redeagroenergia.cnpm.embrapa.br $>$. Acesso em: 12 ago. 2008.
DE SOUZA, P. I.; EGLI, D. B.; BRUENING, W. P. Water stress during seed filling and leaf senescense in soybean. Agronomy Journal, Madison, v. 89, n. 5, p. 807812, 1997.

DESCLAUX, D.; HUYNH, T.; ROUMET, P. Identification of soybean plant characteristics that indicate the timing of drought stress. Crop Science, Madison, v. 40, n. 3, p. 716-722, 2000.

EMPRESA BRASILEIRA DE PESQUISA AGROPECUÁRIA - EMBRAPA. Centro Nacional de Pesquisa de Solos (Rio de Janeiro, RJ). Sistema brasileiro de classificação de solos. Brasília: Embrapa, 2006a. 306 p.

Tecnologias de produção de soja - Paraná 2007. Londrina: Embrapa Soja, 2006b. 217 p. (Sistemas de Produção, 10).

Tecnologias de produção de soja - Região

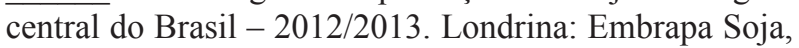
2011. 262 p. (Sistemas de Produção / Embrapa Soja, 15).

FARIAS, J. R. B.; NEPOMUCENO, A. L.; NEUMAIER, N. Ecofisiologia da soja. Londrina: Embrapa Soja, 2007. 10 p. (Embrapa soja, circular técnica, 48).

FEHR, W. R.; CAVINESS, C. E. Stage of soybean development. Ames: Iowa State University, 1977. 11 p.

FERREIRA, D. F. Análises estatísticas por meio do Sisvar para Windows versão 4.0. In: REUNIÃO ANUAL DA REGIÃO BRASILEIRA DA SOCIEDADE INTERNACIONAL DE BIOMETRIA, 45., 2000, São Carlos, SP. Anais... UFSCar: São Carlos, jul. 2000. p. 255-258.

FRANÇA NETO, J. B.; KRZYZANOWSKI, F. C. Sementes enrugadas: novo problema na soja. Londrina: EMBRAPA-CNPSo, 1990. 4 p. (Comunicado técnico, 46).

GUIMARÃES, F. S.; REZENDE, P. M.; CASTRO, E. M.; CARVALHO, E. A.; ANDRADE, M. J. B. de; CARVALHO, E. R. Cultivares de soja [Glycine Max (L.) Merrill] para cultivo de verão na região de lavras-MG. Ciência e Agrotecnologia, Lavras, v. 32, n. 4, p. 10991106, 2008.

HEIFFIG, L. S.; CÂMARA, G. M. S.; MARQUES, L. A.; PEDROSO, D. B.; PIEDADE, S. M. S. Fechamento e índice de área foliar da cultura da soja em diferentes arranjos espaciais. Bragantia, Campinas, v. 65, n. 2, p. 285-295, 2006.

INSTITUTO AGRONÔMICO DO PARANÁ - IAPAR. Clima do Paraná. 2008. Disponível em: <http://www. iapar.br/>. Acesso em: 12 set. 2008. 
MARTINS, M. C.; CÂMARA, G. M. S.; PEIXOTO, C. P.; MARCHIORI, L. F. S.; LEONARDO, V.; MATTIAZZI, P. Épocas de semeadura, densidades de plantas e desempenho vegetativo de cultivares de soja. Scientia Agricola, Piracicaba, v. 56, n. 4, p. 851-858, 1999.

MATZENAUER, R.; BARNI, N. A.; MALUF, J. R. T. Estimativa do consumo relativo de água para a cultura da soja no Estado do Rio Grande do Sul. Ciência Rural, Santa Maria, v. 33, n. 6, p. 1013-1019, 2003.

MEDINA, P. F.; RAZERA, L. F.; MARCOS FILHO, J,. BORTOLETTO, N. Produção de sementes de cultivares precoces de soja em duas épocas e dois locais paulistas: I. características agronômicas e produtividade. Bragantia, Campinas, v. 56, n. 2, p. 291-303, 1997.

NEUMAIER, N.; NEPOMUCENO, A. L.; FARIAS, J. R. B.; OYA, T. Estádios de Desenvolvimento da Cultura de Soja. In: BONATO, E. R. (Ed.). Estresses em soja. Passo Fundo: Embrapa Trigo, 2000. 254 p.

PEIXOTO, C. P.; CÂMARA, G. M. S.; MARTINS, M. C.; MARCHIORI, L. F. S. Características agronômicas e rendimento de soja em diferentes épocas de semeadura e densidade de plantas. Magistra, Cruz das Almas, v. 13, n. 2, jul./dez. 2001. Disponível em: <http://www.magistra. ufrb.edu.br/publica/magist13_2/01-13_2-06c.html>. Acesso em: 13 maio 2011.

PIMENTEL-GOMES, F.; GARCIA, C. H. Estatística: aplicada a experimentos agronômicos e florestais: exposição com exemplos e orientação para uso de aplicativos. Piracicaba: FEALQ, 2002. 309 p.
RANGEL, M. A. S.; MINUZZI, A.; BRACCINI, A. L.; SCAPIM, C. A.; CARDOSO, P. C. Efeitos da interação genótipos $\mathrm{x}$ ambientes no rendimento de grãos e nos teores de proteína de cultivares de soja. Acta Scientiarum. Agronomy, Maringá, v. 29, n. 3, p. 351-354, 2007.

SCOTT, A.; KNOTT, M. Cluster-analysis method for grouping means in analysis of variance. Biometrics, Washington D.C., v. 30, n. 3, p. 507-512, 1974.

TAWARE, S. P.; HALVANKAR, G. B.; RAUT, V. M.; PATIL, V. P. Variability, correlation and path analysis in soybean hybrids. Soybean Genetics Newsletter, Ames, v. 24, n. 1, p. 96-98, 1997.

USDA - Foreign Agricultural Services. Commodities and products: oilseeds. 2012. Disponível em: <http:// www.fas.usda.gov>. Acesso em: 10 abr. 2012.

WELLS, R. Dynamics of soybean growth in variable planting patterns. Agronomy Journal, Madison, v. 1, n. 81, p. 44-48, 1993.

WELLS, R. Soybean growth response to plant density: relationships among photosynthesis, leaf area, and light interception. Crop Science, Madison, v. 31, n. 3, p. 755 756, 1991.

WHIGHAM, D. K.; MINOR, H. C. Agronomic characteristics and environmental stress. In: NORMAN, A. G. (Ed.). The soybeans: physiology, agronomy and utilization. New York, Academic Press, 1967. p. 78-105.

YOKOMIZO, G. K. Interação genótipos $x$ ambientes em topocruzamentos de soja tipo alimento com tipo grão. 1999. Tese (Doutorado em Genética e Melhoramento de Plantas) - Escola Superior de Agricultura Luis de Queiroz, Piracicaba. 